\title{
Vulnerability to Reentry during the Acute Phase of Myocardial Ischemia: a Simulation Study
}

\author{
JM Ferrero (Jr), B Trénor, F Montilla, J Sáiz, JM Alonso, G Moltó
}

Centre for Research and Innovation in Bioengineering, Universidad Politécnica, Valencia, Spain

\begin{abstract}
The aim of this work was to analyze the vulnerability to reentry in a two-dimensional sheet of regionallyischemic and anisotropic myocardial tissue at different stages of acute myocardial ischemia. We used computer modelling in order to elucidate the main factors responsible for initiation and maintenance of reentry.

Simulations were carried out using a modified version of the Luo-Rudy-II model. The simulated 2D tissue included a central ischemic zone, a border zone and a normal zone and was prematurely stimulated. The degree of severity of the central zone was changed depending on the stage of acute ischemia.

Our results offer a theoretical explanation of the existence of a vulnerable phase for reentry between the fifth and tenth minute of acute ischemia, and lead to the conclusion that (a) strong hyperkalemia is needed to sustain reentry and (b) severe degrees of hypoxia tend to reduce myocardial vulnerability to reentry.
\end{abstract}

\section{Introduction}

Ventricular tachycardia and ventricular fibrillation are potentially mortal arrhythmias caused by reentrant electrical activity in the heart ventricles [1]. Although they may occur in normal healthy myocardium under certain circumstances, they are usually a consequence of the electrophysiological changes caused by acute myocardial ischemia [1,2]. If ischemia is regional, the inhomogeneities developed in the myocardium seriously predispose the substrate to reentry [1-5].

Experimental evidence has shown that several minutes after coronary artery occlusion, reentrant activity following premature stimulation may have the form of a figure-of-eight, with two parallel reentrant circuits circulating around an area of functional block [3-6]. This pattern may be stable (ventricular tachycardia) or may destabilize, leading to ventricular fibrillation $[3,5]$. Other experimental works show that the incidence of these types of arrhythmias is higher during the fifth and sixth minute after the occlusion, ceasing after 10 minutes of ischemia $[7,8]$.
In this paper, we present a theoretical study of the mechanisms of figure-of-eight reentry during the acute phase of regional myocardial ischemia, focusing on the influence of the degree of hypoxia (and, therefore, the degree of activation of the ATP - sensitive $\mathrm{K}^{+}$current, $\left.\mathrm{I}_{\mathrm{K}(\mathrm{ATP})}[9,10]\right)$, acidosis and hyperkalemia on the vulnerability to reentry. Mathematical models were used to simulate electrical activity of a virtual tissue which imitated the conditions of regional acute ischemia. The main results show that the likelihood of figure-of-eight reentry increases with time after the coronary artery occlusion, reaches a peak and finally decreases to zero after 10-12 minutes of ischemia.

\section{Methods}

The dynamic Luo-Rudy (phase II) equations [11,12] were chosen as the model to simulate the cardiac action potentials and the underlying ionic currents due to its comprehensiveness. To simulate acute ischemia, its three main components were considered. Firstly, hypoxia was modelled by partially activating the ATP-sensitive $\mathrm{K}^{+}$ current $\left(\mathrm{I}_{\mathrm{K} \text { (ATP) }}\right)$, using the mathematical formulation of Ferrero Jr et al [10]. Secondly, hyperkalemia was simulated by elevating extracellular $\mathrm{K}^{+}$concentration $\left(\left[\mathrm{K}^{+}\right]_{\mathrm{o}}\right)$. Finally, acidosis was modelled by its effect on the $\mathrm{Na}^{+}$and $\mathrm{Ca}^{2+}$ currents $[13,14]$ as described below.

Although the myocardium is a three dimensional structure, we used a $5.5 \mathrm{~cm}$ x $5.5 \mathrm{~cm}$ two-dimensional tissue in our simulations. Figure 1 shows the structure of the virtual tissue which, in order to properly simulate regional acute ischemia, comprises three different zones. A circular shaped central ischemic zone $(\mathrm{CZ}, 20 \mathrm{~mm}$ in diameter [15]) is formed by cells directly affected by the lack of blood flow. Inside this zone, the values of the parameters affected by ischemia were chosen to correspond to their experimental values measured at different instants after the onset of ischemia. $\left[\mathrm{K}^{+}\right]_{\mathrm{o}}$ was set to a value in the range $5.4-12.5 \mathrm{mmol} / \mathrm{L}[9,15]$ to simulate hyperkalemia; the fast inward $\mathrm{Na}^{+}$current $\left(\mathrm{I}_{\mathrm{Na}}\right)$ and the $\mathrm{Ca}^{2+}$ current through the L-type channels $\left(\mathrm{I}_{\mathrm{Ca}(\mathrm{L})}\right)$ were scaled by a factor $f_{p H}$ in the range 1.0-0.7 to simulate the main effects of intracellular and extracellular acidosis $[13,14]$; and intracellular levels of ATP and ADP 
$\left([\mathrm{ATP}]_{\mathrm{i}}\right.$ and $\left.[\mathrm{ADP}]_{\mathrm{i}}\right)$ were set to values in the range 6.8$4.2 \mathrm{mmol} / \mathrm{L}$ and $15-200 \mu \mathrm{mol} / \mathrm{L}$ respectively to mimic hypoxia [9,10]. These values of intracellular ATP and ADP levels yield fractions of activated $K_{\text {ATP }}$ channels $\left(\mathrm{f}_{\text {ATP }}\right)$ in the range $0.05-0.9 \%$ [10].

To represent the structure of a regional acute ischemic tissue in a realistic way $[1,3,15]$, a $10 \mathrm{~mm}$ ring-shaped ischemic border zone (BZ) was defined around the $\mathrm{CZ}$. According to experimental data from Coronel [15], and choosing a linear approximation for the gradients of the relevant parameters, $\left[\mathrm{K}^{+}\right]_{\text {o }}$ was set to change from 5.4 $\mathrm{mmol} / \mathrm{L}$ to its ischemic value across the $10 \mathrm{~mm} \mathrm{BZ}$. Similarly, factor $\mathrm{f}_{\mathrm{pH}}$ was varied from 1.0 to its ischemic value across the $\mathrm{pH}$ border zone $5 \mathrm{~mm}$ in width [13-15]. As for $[A T P]_{i}$ and $[A D P]_{i}$ (and thus $f_{A T P}$ ), they were varied across the $1 \mathrm{~mm} \mathrm{pO}_{2}$ border zone [15]. All the spatial gradients of parameters mentioned above are graphically shown in Figure 1.

The simulated tissue was considered anisotropic, with the longitudinal and transverse passive resistances chosen to yield a longitudinal conduction velocity of around 50 $\mathrm{cm} / \mathrm{s}$ in normal tissue, with an anisotropy velocity ratio of 4:1 [16].

The lower border of the tissue was first stimulated with a rectangular pulse $2 \mathrm{~ms}$ in duration and 1.5 times diastolic threshold (stimulus $\mathrm{S}_{1}$ ). A second premature pulse $\left(\mathrm{S}_{2}\right)$ was delivered at the same location with different coupling intervals $(\mathrm{CI})$. The vulnerable window (VW) for reentry was defined as the interval of CIs which yielded reentrant activity in the tissue.

\section{Results and discussion}

In each set of simulations, the values chosen for $\left[\mathrm{K}^{+}\right]_{\mathrm{o}}$, $f_{\mathrm{pH}}$ and $f_{\mathrm{ATP}}$ in the $\mathrm{CZ}$ (see Figure 1) were kept constant. The onset and offset of the VW were determined by delivering the premature stimulus $\mathrm{S}_{2}$ at different $\mathrm{CI}$ values after $S_{1}$ was delivered. When $S_{2}$ was applied inside the VW, figure-of-eight reentry was obtained.

Figure 2 shows an example of such reentry pattern. Each panel in the figure shows a gray-coded voltage snapshot representing the electrical state of the tissue at different time instants after the delivery of $\mathrm{S}_{2}$. The snapshots shown are separated by $50 \mathrm{~ms}$ intervals, the first one corresponding to $50 \mathrm{~ms}$ after the delivery of the premature stimulus. The simulation was carried out using $\mathrm{CZ}$ values of $\left[\mathrm{K}^{+}\right]_{\mathrm{o}}=12.5 \mathrm{mmol} / \mathrm{L}, f_{\mathrm{pH}}=0.75$ and $f_{\mathrm{ATP}}=$ $0.4 \%$, while the CI of the second stimulus was $218 \mathrm{~ms}$.

In the 1 st and 2 nd snapshots (50 and $100 \mathrm{~ms}$ after the delivery of $\mathrm{S}_{2}$, respectively), a conduction block develops in the proximal side of the BZ. In the second and third snapshots, the wavefront is surrounding the zone of block, which is still refractory. In the fourth and fifth snapshots, the wavefront is retrogradely invading the $\mathrm{CZ}$, once its refractory period has finished and it has recovered excitability. In the sixth and seventh snapshot, the propagated action potential is re-emerging in the proximal side of the NZ and reentry is being developed. In the eighth and ninth snapshots, an ectopic beat is being produced, with the wavefront re-exciting zones which had been previously excited by $\mathrm{S}_{2}$. In the rest of the snapshots, the reentry process is repeated, and four and a half reentry cycles have been completed at the instant of the last snapshot shown.

The patterns of excitation shown in Figure 2 are very similar to those obtained experimentally under similar regional acutely ischemic conditions (e.g. see Fig. 8 in [3], Fig. 3 in [4] or Fig. 5 in [6]). The mechanisms that cause the unidirectional block in the proximal part of the BZ are similar in our simulations and in the experiments: the development of postrepolarization refractoriness in the zones with severe hyperkalemia $(\mathrm{CZ}$ and innermost part of the BZ) makes this zone of the tissue unexcitable when the incoming wavefront arrives, and the low conduction velocity with which the wavefront surrounds the zone of block gives time to this zone to recover excitability.

The ischemic $\mathrm{CZ}$ values of $\left[\mathrm{K}^{+}\right]_{\mathrm{o}}, f_{\mathrm{pH}}$ and $f_{\mathrm{ATP}}$ were different in each simulation set, in order to measure the duration of the $\mathrm{VW}$ in different ischemic situations. When varying $\left[\mathrm{K}^{+}\right]_{\mathrm{o}}$, the results indicate that the $\mathrm{VW}$ was inexistent (duration zero, and therefore reentry was impossible to induce) for concentrations below 11.9 mmol/L regardless of the values of $f_{p H}$ and $f_{\text {ATP. Thus, }}$. strong hyperkalemia is needed to produce reentry in the model. This limiting value roughly corresponds to the plateau phase of extracellular $\mathrm{K}^{+}$accumulation in acute ischemia $[9,15]$.

The effect of the other two relevant ischemic parameters on the duration of the VW was not so dramatic. If $\left[\mathrm{K}^{+}\right]_{\mathrm{o}}$ was set to $12.5 \mathrm{mmol} / \mathrm{L}$ and $\mathrm{f}_{\mathrm{pH}}$ was kept constant, the duration of the $\mathrm{VW}$ changed with $\mathrm{f}_{\mathrm{ATP}}$ in a biphasic manner. For example, for $\mathrm{f}_{\mathrm{pH}}=0.75$ (which corresponds to $\mathrm{pH} \approx 6.4$ ), the duration of the $\mathrm{VW}$ was 0 $\mathrm{ms}$ for $\mathrm{f}_{\mathrm{ATP}}=0.1 \%$, increased and peaked at $45 \mathrm{~ms}$ for $\mathrm{f}_{\mathrm{ATP}}=0.4 \%$, and decreased to $13 \mathrm{~ms}$ for $\mathrm{f}_{\mathrm{ATP}}=0.7 \%$ and $0 \mathrm{~ms}$ for $\mathrm{f}_{\text {ATP }}>0.95 \%$. If $\mathrm{f}_{\text {ATP }}$ was held constant, the VW duration also varied biphasically with $\mathrm{f}_{\mathrm{pH}}$.

During an ischemic episode, $\left[\mathrm{K}^{+}\right]_{\mathrm{o}}$ increases in the $\mathrm{CZ}$ from its normal value to about $12-13 \mathrm{mmol} / \mathrm{L}$ and reaches a plateau in the first 5-10 minutes after the onset of ischemia, with the time to the plateau depending on the animal species and pacing rate [2,9]. In addition, $\mathrm{pH}$ decreases around 1 unit and $\mathrm{f}_{\mathrm{ATP}}$ increases to about 0.7 $0.9 \%[9,10]$ during the first $10-12$ minutes of ischemia. Combining the results of different simulations, we can plot the time course of the VW duration as ischemia progresses. This is shown in Figure 3, where the time course of $\left[\mathrm{K}^{+}\right]_{\mathrm{o}}, \mathrm{f}_{\mathrm{pH}}$ and $\mathrm{f}_{\mathrm{ATP}}$ is shown in the left panel and the VW durations are shown on the right panel. To build this figure, it has been assumed that $\mathrm{pH}$ and $\mathrm{K}_{\mathrm{ATP}}$ current 

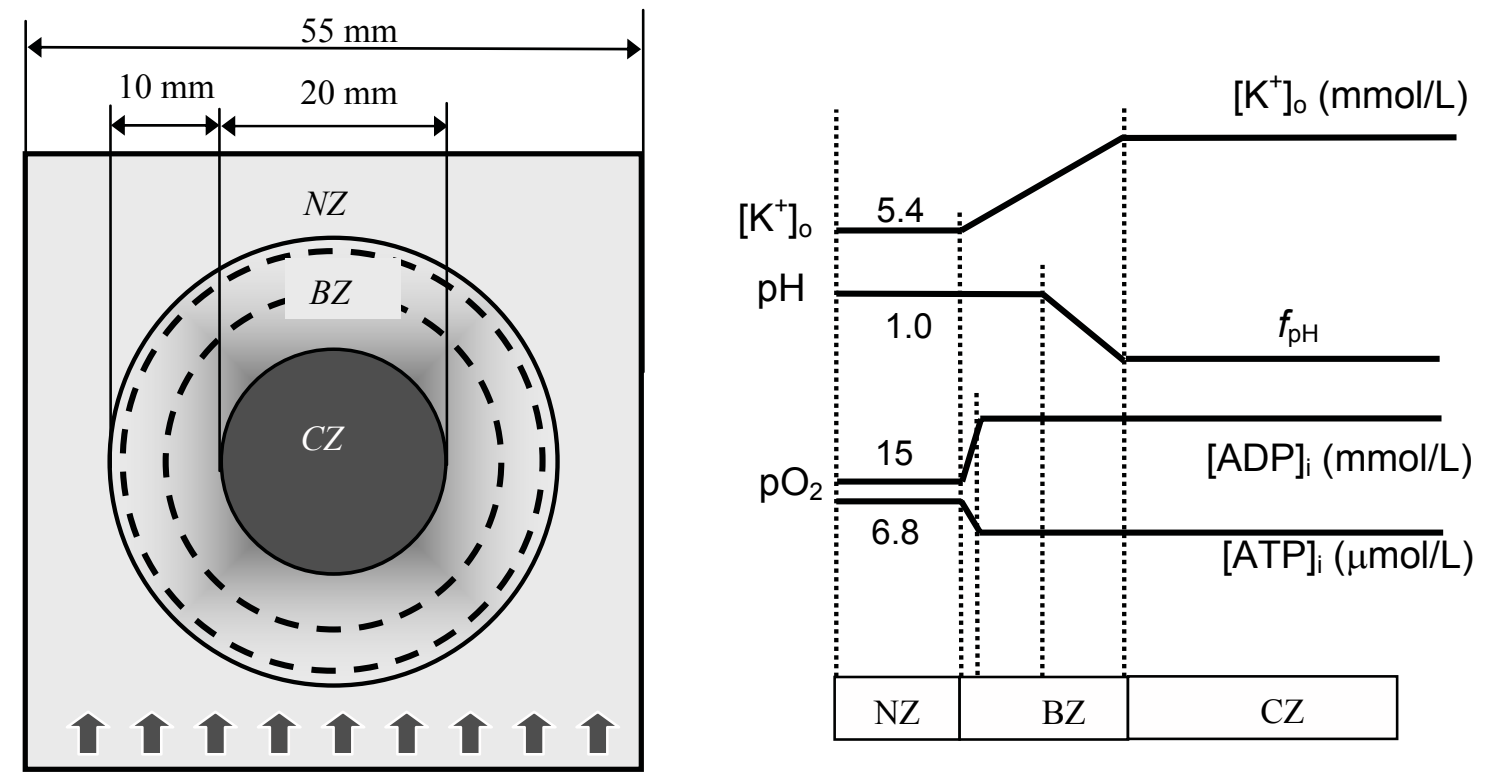

Figure 1. Schematic of the 2D virtual tissue. Left panel: structure of the tissue. Right panel: variations of relevant parameters affected by ischemia (see text for details). The values of said parameters within the $\mathrm{CZ}$ where varied through the simulations.

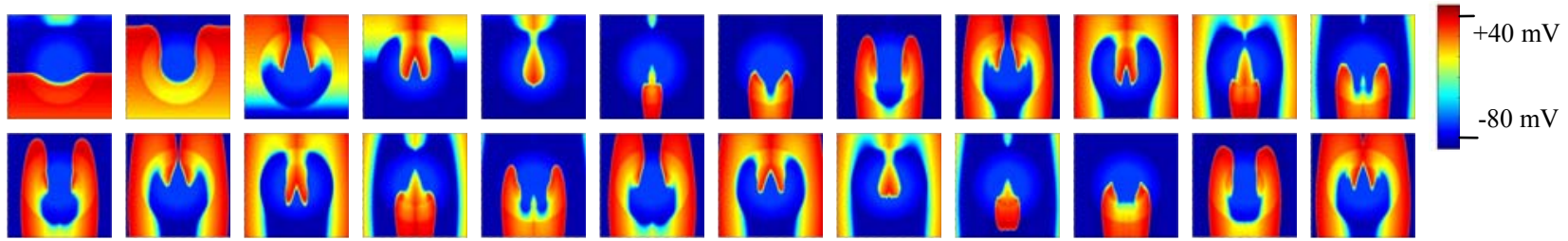

Figure 2. Example of figure-of-eight reentry in the simulated tissue. Each panel represents a grey-coded voltage snapshots of the tissue after stimulation with $\mathrm{S}_{2}$. Snapshots are separated by $50 \mathrm{~ms}$ intervals. See text for details.
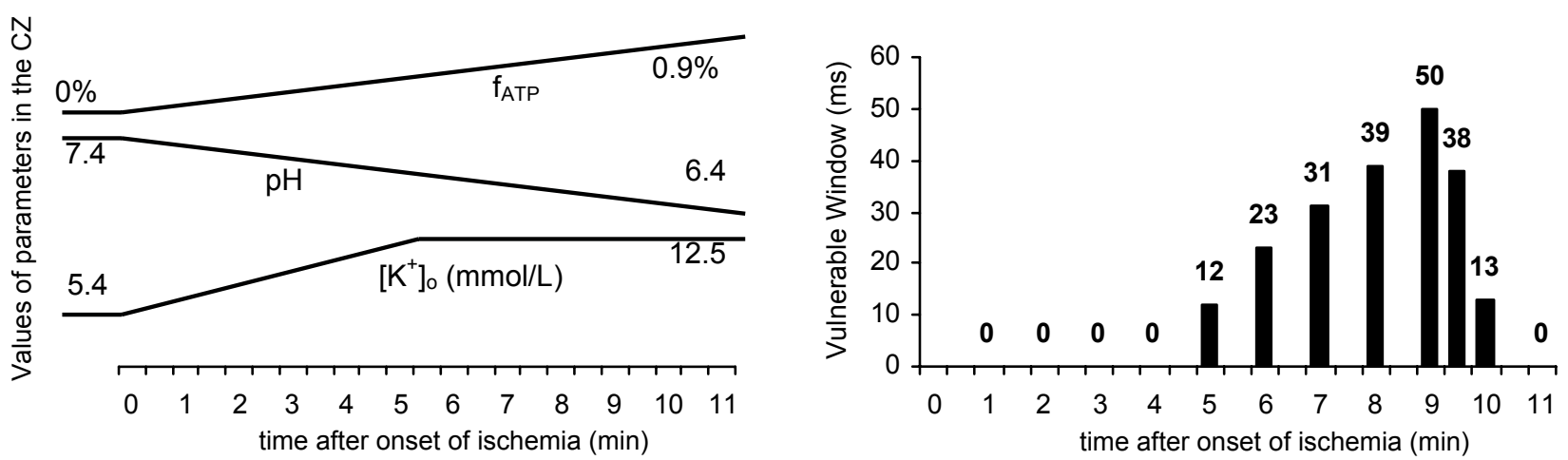

Figure 3. Left panel: time course of relevant parameters inside the CZ. Right panel: time course of the duration of the vulnerable window (VW) for reentry. Numbers over each bar indicate duration of the VW in $\mathrm{ms}$. 
degree of activation $\left(f_{\text {ATP }}\right)$ vary linearly with time, while $\left[\mathrm{K}^{+}\right]_{\mathrm{o}}$ reaches its plateau 5 minutes after the onset of ischemia.

The results shown in Figure 3 indicate that the duration of the VW is zero until the fifth minute of ischemia, when it begins to increase. It peaks in the ninth minute before rapidly decreasing again. Finally, the VW vanishes after the eleventh minute. This result agrees with experimental observations according to which the first period of arrhythmias after coronary occlusion finishes around the tenth minute and peaks at 5-6 minutes after the onset of ischemia $[7,8]$.

\section{Conclusions}

Figure-of-eight reentry, a pathological and arrhythmic pattern of activation observed experimentally under regional acute ischemic conditions, was successfully simulated using a second-generation action potential and ionic current model, together with a model of ischemia in a realistically heterogeneous anisotropic virtual heart bidimensional tissue. The patterns of excitation obtained in our simulations closely resembled those obtained under comparable experimental conditions. When simulating the time-course of ischemia, the vulnerable window for reentry begins to increase after the fifth minute and peaks at the ninth minute, vanishing two minutes later. The results show that strong hyperkalemia $\left([\mathrm{K}+]_{\mathrm{o}}>11.9 \mathrm{mmol} / \mathrm{L}\right)$ is needed to sustain reentry. In addition, the simulations show that the vulnerable window vanishes at moderately high degrees of $\mathrm{K}_{\mathrm{ATP}}$ channel activation $\left(\mathrm{f}_{\mathrm{ATP}}>0.95 \%\right)$, encouraging the possibility of using pharmacological agents that modulate $\mathrm{K}_{\mathrm{ATP}}$ current (e.g. pinacidil, a $\mathrm{K}_{\mathrm{ATP}}$ channel activator) as antiarrhythmic agents.

\section{Acknowledgements}

This work was partially supported by the Plan Nacional de Investigación Científica, Desarrollo e Innovación Tecnológica del Ministerio de Ciencia y Tecnología of Spain (TIC 2001-2686).

\section{References}

[1] Wit A, Janse MJ. The ventricular arrhythmias of ischemia and infarction. Electrophysiological mechanisms. Mount Kisco, NY: Futura Publishing Company, 1993.

[2] Janse MJ, Wit A. Electrophysiological mechanisms of ventricular arrhythmias resulting from myocardial ischemia and infarction. Physiol. Rev. 1989, 69(4):1049-1169.

[3] Janse MJ et al. Flow of injury current and patterns of excitation during early ventricular arrhythmias in acute regional myocardial ischemia in isolated porcine and canine hearts. Circ. Res. 1980, 47(2):151-165.

[4] Janse MJ, Kleber AG. Electrophysiological changes and ventricular arrhythmias in the early phase of regional myocardial ischemia. Circ. Res. 1981, 81(5):1069-1081.

[5] Kleber AG. Conduction of the impulse in the ischemic myocardium - implications for malignant ventricular arrhythmias. Experientia, 1987, 43(10):1056-1061.

[6] Costeas C, Peters NS, Waldecker B, Ciaccio EB, Wit AL, Coromilas J. Mechanisms causing sustained ventricular tachycardia with multiple QRS morphologies. Circulation 1997, 96(10):3721-3731.

[7] Kaplinsky E, Ogawa S, Balke CW, Dreifus LS. Two periods of early ventricular arrhythmia in the canine acute myocardial infarction model. Circulation 1979, 60(2):397403.

[8] Ogawa S, Nakamura Y, Dreifus LS, Kaplinsky E. Ventricular arrhythmias in acute coronary artery ligation in dogs: electrophysiological mechanism and its relation to the severity of myocardial ischemia. Jap. Circ. J. 1981, 45: 517-523.

[9] Weiss JN, Venkatesh N, Lamp ST. ATP-sensitive $\mathrm{K}^{+}$ channels and cellular $\mathrm{K}^{+}$loss in hypoxic and ischaemic mammalian ventricle. J. Physiol. (Lond.) 1992, 447:649673.

[10] Ferrero (Jr) JM, Saiz J, Ferrero JM, Thakor NV. Simulation of action potentials from metabolically impaired cardiac myocytes. Role of ATP-sensitive $\mathrm{K}^{+}$current. Circ. Res. 1996, 79:208-221.

[11] Luo CH, Rudy Y. A dynamic model of the cardiac ventricular action potential. I. Simulations of ionic currents and concentration changes. Circ. Res. 1994, 74:1071-1096.

[12] Zeng J, Laurita KR, Rosenbaum DS, Rudy Y. Two components of the delayed rectifier $\mathrm{K}+$ current in ventricular myocytes of the guinea pig type. Theoretical formulation and their role in repolarization. Circ. Res. 1995, 77(1):140-152.

[13] Yatani A, Brown AM, Akaike N. Effect of extracellular $\mathrm{pH}$ on sodium current in isolated, single rat ventricular cells. J. Membr. Biol. 1984, 78(2):163-168.

[14] Irisawa H, Sato R. Intra- and extracellular actions of proton on the calcium current of isolated guinea pig ventricular cells. Circ. Res. 1986, 59(3):348-355.

[15] Coronel R. Heterogeneity in extracellular potassium concentration during early myocardial ischaemia and reperfusion: implications for arrhythmogenesis. Cardiovasc. Res. 1994, 28(6):770-777.

[16] Leon LJ, Roberge FA, Vinet A. Simulation of twodimensional anisotropic cardiac reentry: effects of the wave length on the reentry characteristics. Ann. Biomed. Eng. 1994, 22(6):592-609.

Address for correspondence.

José M. Ferrero (Jr)

Departamento de Ingeniería Electrónica, Universidad Politécnica de Valencia, Camino de Vera s/n, 46020 Valencia, Spain.

cferrero@eln.upv.es 